\title{
EFEITO DO SISTEMA DE ROTAÇÃO DE TERRA NOS PROCESSOS DE VERTENTE -GUARAPUAVA-PR*
}

\author{
Edivaldo Lopes Thomaz**
}

\section{RESUMO}

O uso da terra é um dos principais fatores controladores dos processos de vertente. A influência do sistema de rotação de terras nos processos hidrológicos de vertente é escasso na região centro-sul do Paraná. Assim, o objetivo desse estudo foi verificar o efeito do sistema de rotação de terras nos processos hidrológicos de vertente declivosa recoberta por solos rasos. Foi realizado mapeamento prévio da área estudada, em seguida foram realizados diversos monitoramentos em campo (ex. características físicohídricas dos solos, escoamento, umidade do solo e interceptação). A base teórica para interpretação dos processos de vertente seguiu a proposição de DALRYMPLE et al. (1968) (Hypothetical nine-unity lansurface mode/). Verificou-se que a dinâmica do sistema de rotação de terras aliado a complexidade geomorfopedológica da vertente induz processos hidrológicos subsuperficiais. Esses processos são fundamentais para o desencadeamento de instabilidade nas vertentes através do surgimento e expansão de canais de primeira ordem.

Palavras-chave: uso da terra, processo de vertente, instabilidade

\section{ABSTRACT}

The land use is one of the main controlling factors on hillslope processes. The land rotation system has influences on the hillslope hydrological processes; also this information is scarce in the center-south Paraná region. Hence, this study has as its aim to verify the land rotation system effects on hydrological processes related to steep slope covered by shallow soil. Previous mapping of the study area was carried out, afterward a range of field measurement was done (e.g soil physical-hydric characteristics; runoff, soil humidity and interception). The theoretical base for interpretation of the hillslope processes followed the DALRYMPLE et al. (1968) proposal (Hypothetical nine-unity lansurface model). It was verified that the land rotation system dynamics as well the hillslope geomorphopedological complexity induces subsurface hydrological processes. These processes are fundamental to hillslope instability triggering, also to developing and expanding the first-order canal.

Keywords: land use, hillslope processes, instability

\section{Introdução}

Os processos de vertente são centrais aos propósitos da Geomorfologia (CHORLEY, 1964). A importância dos estudos de vertente tem levado ao surgimento de especialidades como: hidrologia de vertente (McCAIG, 1985) e mais recentemente a proposição de uma nova ciência, hidrogeomorfologia (SIDLE \& ONDA, 2004). Nas

\footnotetext{
*Este trabalho é parte da tese de doutoramento, Processos hidrogeomorfológicos e o uso da terra em ambiente subtropical - Guarapuava - PR, defendida em 2005 junto ao programa de Pós-Graduação em Geografia Física da Faculdade de Filosofia Letras e Ciências Humanas, Universidade de São Paulo. ${ }^{* *}$ Pesquisador do CNPq, Professor Adjunto da Universidade Estadual do Centro-Oeste - UNICENTRO, Departamento de Geografia, Rua Simeão Camargo Varela de Sá, 03 - Cx. Postal, 3010 Fone (042) $3629-8117$ - $3629-8133$ 
últimas décadas foram obtidos muitos avanços acerca dos processos hidrológicos em vertente e cabeceira de drenagem (KIRKBY, 1978, ANDERSON \& BURT, 1990, ANDERSON \& BROOKS, 1996).

Dentre os processos de vertente os fluxos subsuperficiais, sobretudo, em forma de túnel (pipe) são importantes, pois eles são responsáveis pela resposta hidrológica de rios (streamflow) (WALSH \& HOWELLS, 1988), formação de canais e outros processos associados (ex. fluxo saturado, fluxo de retorno e transferência de solutos) (ANDERSON \& BURT, 1990) e aumento de produção de sedimento (BRYAN \& JONES, 1997).

A presença de fluxos em túnel nas vertentes está ligada a variados fatores controladores como: solos com diferenças hidráulicas entre horizontes (anisotropia vertical); materiais susceptíveis a contração (argilas expansivas), sazonalidade climática; grande suprimento de água (precipitação abundante) aliado a gradiente hidráulico abrupto devido à variação topográfica; chuvas intensas e frequentes somado ao desflorestamento, entre outros (McCAIG, 1985, JONES et. al., 1997, BRYAN \& JONES, 1997).

A vegetação tem papel importante nos processos de vertente (WALLACE \& OLIVER, 1990, BROOKS, 2003, MORGAN, 2005). Entretanto, a ocupação das vertentes para fins agropecuários leva à retirada da cobertura vegetal, disso resulta em profundas transformações hidrogeomorfológicas. Existem práticas agrícolas tradicionais em que o uso da terra é cíclico. Ou seja, a vegetação é roçada e queimada, em seguida é feito o cultivo. Na sequência, o terreno é deixado em regeneração e retorna a ser ocupado em torno de cinco anos mais tarde. Essas práticas são usuais em diversas regiões como: Amazônia brasileira (HÖLSCHER, et al., 1997), Argentina e Bolívia (GRAU \& BROWN, 2000) e Bangladesh (BORGGAARD et al., 2003). Esse manejo da terra é comum em Guarapuava (THOMAZ, 2009), bem como no Centro Sul do Paraná, todavia seus efeitos nos processos hidrológicos de vertente são escassos.

De tal modo, os objetivos desta pesquisa foram: 1) avaliar as características físico-hídricas do solo em vertente ocupada por sistema de rotação de terras; 2 ) comparar o escoamento superficial em área com capoeira e área queimada; 3) mensurar a capacidade de interceptação de chuva em capoeira em regeneração (dossel e serrapilheira); 4) estimar o balanço de água em vertente recoberta por capoeira em regeneração e propor modelo teórico de funcionamento hidrológico.

\section{Área de estudo}

A bacia do Rio Guabiroba faz divisa ao Norte com a bacia do Rio das Pedras e ao Sul com a bacia dos Rios Iratim-Bananas. A disposição predominante da bacia é de Leste para Oeste. A bacia possui área aproximada de $23,7 \mathrm{~km}^{2}$ (2370 ha) e a hierarquia fluvial é de quarta ordem. Já, a cabeceira de drenagem, local de estudo, é de terceira ordem com área de $2,53 \mathrm{~km}^{2}$, densidade de drenagem de $2,87 \mathrm{~km} / \mathrm{km}$ e declividade predominante variando entre $12 \%$ a superior a $30 \%$. Essas declividades correspondem a $75,6 \%$ da área total da bacia.

O clima de Guarapuava está sob o domínio da zona extratropical, o que resulta em temperaturas com caráter mesotérmico. A temperatura anual média é $17,1 \pm 0,47^{\circ} \mathrm{C}$, o inverno é frio e o verão é amenizado pelas altitudes, a evaporação média anual é de $835,1 \pm 123,9 \mathrm{~mm}$. As chuvas são abundantes e distribuídas ao longo do ano (média anual 1953,8 $\pm 389,7 \mathrm{~mm}$ ) (THOMAZ \& VESTENA, 2003).

A rocha predominante da área de estudo é o basalto (Formação Serra Geral). As vertentes possuem forte escalonamento devido aos estratos de basalto (degraus). A distribuição pedológica na área de estudo apresenta três tipos principais: Cambissolo, Neossolo (litólico) e Gleissolo (hidromórfico). Nas unidades pedológicas ocorrem inclusões de afloramento de rocha, pedregosidade e rochosidade em grau variado. Portanto, ocorre a variação desses solos no âmbito da cabeceira de drenagem, onde eles aparecem frequentemente em associação. O relevo desta unidade é predominantemente forte ondulado a montanhoso com declividade superior a $40 \%$. Devido às características descritas essa unidade apresenta suscetibilidade à erosão muito forte, bem como é predisposta a deslizamentos e desmoronamentos (MENDES \& CASTRO, 1984). 


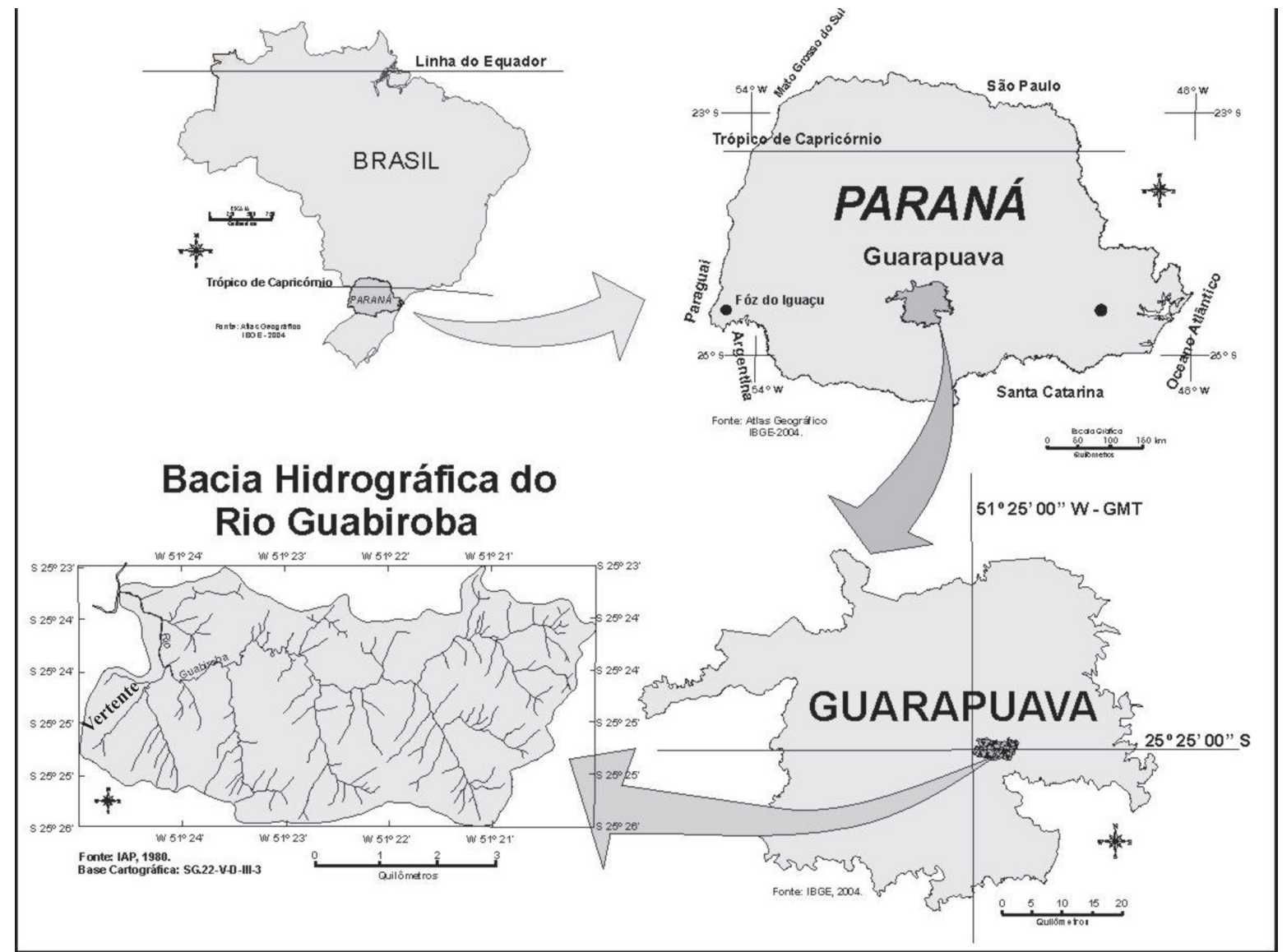

Figura 1 - Localização da área de estudo

O uso da terra é dinâmico na área em estudo, sendo comum encontrar capoeira em diversos estágios de regeneração, áreas mecanizadas em pousio e rotação de terra praticada pela agricultura de subsistência ou de toco. Portanto, o uso da terra muda de um ano para outro e mesmo de uma estação para outra. Essa variabilidade têmporoespacial no uso da terra resulta em um padrão em mosaico (manchas, corredores e faixas).

A roça de toco, denominação regional consiste em se roçar uma área previamente em pousio (capoeira em regeneração) antes da primavera, deixar o material secar sobre o solo e, no início da primavera, pôr fogo para limpar o terreno. Posteriormente, o plantio é feito com matraca (plantadeira manual) sobre os resíduos da queimada. O sistema de rodízio de terras ocorre com intervalo entre 3 a 5 anos (THOMAZ, 2005).

\section{Material e método}

\subsection{Delineamento do Monitoramento}

O mapeamento da área de estudo foi realizado previamente (THOMAZ, 2005). Para se avaliar o efeito do sistema de rotação de terra nos processos hidrológicos de vertente, utilizou-se monitoramento sistemático em campo. Outro procedimento utilizado neste estudo foi a observação direta em campo, que consistiu em 
caminhamentos frequentes na área ao longo de pelo menos um ano hidrológico. As observações foram realizadas em diferentes situações como: período de estiagem, período chuvoso, eventos pluviométricos de alta intensidade e estágio de desenvolvimento das atividades agrícolas. Nessas observações registram-se por meio de fotografias algumas condições existentes em cada situação apontada anteriormente. A observação direta foi complementada pelo monitoramento de vários parâmetros descritos a seguir. Por fim, a base teórica para interpretação dos processos de vertente seguiu a proposta de DALRYMPLE et al. (1968) (Hypothetical nine-unity lansurface model). Em linhas gerais, nesse modelo, os autores destacam que em cada setor de vertente há determinados processos geomorfológicos predominantes que são resultantes da complexa relação entre relevo, solo e água.

\subsection{Parâmetros Físico-hídricos do Solo}

Análise física de solo (densidade aparente e porosidade total) foi feita através de amostras indeformadas utilizando-se anéis volumétricos com 95,5 cm cm $^{3}$ (Equação 1 e 2). Foram retiradas 28 amostras ao acaso entre $0-5 \mathrm{~cm}$ de profundidade (topo do solo). No laboratório, as amostras foram preparadas e levadas para secar em estufa a $105^{\circ} \mathrm{C}$ por 24 horas (Embrapa, 1997). Os parâmetros físicos (densidade aparente e porosidade) total foram obtidos de acordo com (REICHARDT, 1990).

A resistência do solo foi mensurada com um penetrômetro de bolso. Os ensaios com esse instrumento foram realizados após período de chuva suficiente para molhar o topo do solo. A coleta das amostras foi feita na superfície do solo (topo do solo). Foram tomadas 124 amostras ao acaso em toda a vertente.

A umidade do solo foi monitorada em cada unidade geomorfopedológica (topo, vertente retilínea, patamar, vertente convexa e terraço fluvial), por meio de um conjunto de tensiômetros distribuídos nas profundidades de 25, 50, 80 e $120 \mathrm{~cm}$ (detalhamento na Fig. 6). O registro da umidade foi feito a cada 5 dias, seguindo o ritmo da pluviosidade, ao longo do monitoramento. Os tensiômetros, constituído por fios e blocos de gesso, foram acondicionados dentro do solo. Após a instalação, foi possível avaliar de forma direta a disponibilidade e o deficit de água. 0 monitoramento da umidade foi realizado entre 12/09/02 a 13/03/03 (THOMAZ, 2005).

\subsection{Escoamento Superficial}

Uma área com capoeira com aproximadamente três anos de regeneração foi utilizada para o monitoramento. Procedeu-se da seguinte forma: a) uma área permaneceu com capoeira; b) outra parte da mesma área (pareada) foi roçada e queimada. O monitoramento do escoamento superficial foi realizado por meio de parcelas de erosão fechadas com chapas de metal $(2 \times 1 \mathrm{~m})$ (THOMAZ, 2005). A água escoada na parcela era canalizada para uma calha coletora e posteriormente armazenada num reservatório (capacidade de 50 litros). Em cada uma das áreas (capoeira e queimada) foram instaladas três parcelas que foram acompanhadas entre 02/05/03 a 30/04/04. O monitoramento das parcelas ocorreu após cada chuva acumulada em 24 horas. Foram registrados 76 eventos pluviométricos com diferentes características físicas (volume e intensidade).

\subsection{Estoque e Interceptação de Chuva em Serrapilheira}

A avaliação da serrapilheira estocada foi realizada por meio de um quadro de metal com $625 \mathrm{~cm}^{2}$. O quadro era arremessado e as amostras coletadas de maneira aleatória. Ao todo foram coletadas 46 amostras: 15 em março de 2003, 24 em setembro de 2003 e 7 em março de 2004. Foram feitas duas estimativas de interceptação de chuva pela serrapilheira em 08/09/03 após uma chuva de $16,5 \mathrm{~mm}$ (15 amostras) e em 09/03/04 após uma chuva de 9,0 mm ( 7 amostras). Esses dois eventos foram escolhidos, pois eles foram precedidos de um período seco, 14 dias sem chuva, o que permitiu que a serrapilheira ficasse com baixa umidade. Assim, foram coletadas amostras antes da chuva, para se determinar a capacidade de campo da serrapilheira, e depois da chuva, para avaliar a interceptação. Após a coleta, o material 
foi secado em estufa a $60{ }^{\circ} \mathrm{C}$ por 24 horas, em seguida foi pesado (Equação 3 e 4).

\subsection{Interceptação de Chuva}

O monitoramento da interceptação de chuva em capoeira foi realizado entre 19/06/03 a $30 / 04 / 2004$, neste período foram registrados 68 eventos pluviométricos com variadas características físicas, especialmente, volume e intensidade. Os interceptômetros com $20 \mathrm{~cm}$ de diâmetro foram instalados embaixo da capoeira, ficando a borda

$$
\begin{aligned}
& \text { Equação 1 - Densidade aparente } \\
& d_{a}=\frac{m_{x}}{V} \\
& \text { Em que: } \\
& d_{a}=\text { densidade aparente } \\
& m_{x}=\text { massa seca } \\
& V=\text { volume do anel }
\end{aligned}
$$

\section{Equação 3 - Interceptaçăo em serrapilheira} $I \%=\frac{A R M_{\text {nos }}}{P} \times 100$

Em que:

$$
\begin{aligned}
1 \% & =\text { interceptaçăo } \\
A R M_{\text {mon }} & =\text { armazenamento em } \mathrm{mm} \\
\mathrm{P} & =\text { precipitaçăo }
\end{aligned}
$$

coletora a aproximadamente $0,5 \mathrm{~m}$ de altura em relação ao solo. Os nove inteceptômetros foram distribuídos ao acaso em vários pontos da área monitorada (em torno de $1500 \mathrm{~m}^{2}$ ). Os interceptômetros, além de serem distribuídos ao acaso, seguiram também o sistema de rodízio proposto por DUNNE \& LEOPOLD (1978). Nesse procedimento, os coletores são deslocados para outro ponto após algumas chuvas (em torno de 5 chuvas). Deste modo, buscou-se melhor avaliar a diversidade interna da capoeira (Equação 5). Ressalta-se que este é o mesmo local onde foi monitorado o escoamento superficial.

\section{Equação 2-Porcsidade total}

$$
\alpha=\left(1-\frac{d_{a}}{2,65}\right) \times 100
$$

\section{Em que:}

$\alpha=$ porosidade total

$d_{a}=$ densidade aparente

$2,65=$ densidade das particulas

Equação 4 - Estoque de serr api heira

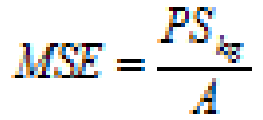

Emque:

MSE= Matéria seca estocada

$P S_{\text {lg }}=$ Peso seco em quilo

$\mathrm{A}=$ área do coletor
Equação 5 - Perda por interceptaçăo no dossel

$$
\mathrm{I}=\mathrm{PT}-\mathrm{PI}
$$

Em que:

k interceptaçăo $(\mathrm{mm})$

$\mathrm{PT}=$ precipitácăo total $(\mathrm{mm})$

$\mathrm{Pl}=$ precipitaçà interna $(\mathrm{mm})$.

\subsection{Monitoramento da Precipitação}

A precipitação foi registrada por uma mini-estação meteorológica (WM-918 Electronic Weather Station) instalada distante em torno de
500 metros do local monitorado. Além da estação, foram utilizados 2 pluviômetros (Hel/mann) instalados próximos ao local monitorado. A estação foi programada para registrar a intensidade da precipitação em intervalos de 30 minutos. 
As análises dos dados consistiram na aplicação de estatística descritiva (média, desvio padrão, coeficiente de variação), regressão simples e análise variância (Teste $t$ ). Antes da aplicação do referido teste os dados foram transformados (Log de base 10) para normalizar a variância (VIEIRA, 1999).

\section{Resultados e Discussão}

\subsection{Parâmetros Físico-Hídricos do Solo}

Os parâmetros avaliados no topo do solo indicaram baixa densidade e alta porosidade. Esses indicadores são corroborados pela baixa resistência do material avaliados com penetrômetro (Tabela 1). Em outro estudo realizado nas mesmas condições geomorfopedológicas foram confirmadas as melhores condições físicas do solo em área de rodízio de terras em comparação a outros usos como: pastagens, agricultura mecanizada, pousio entre outros (THOMAZ, 2005). Nesses usos, a densidade aparente variou entre $0,95 \mathrm{~g} / \mathrm{cm}^{3}$ até $1,32 \mathrm{~g} / \mathrm{cm}^{3}$, enquanto a porosidade total variou entre $64,3 \%$ a $50,1 \%$. Já a resistência superficial nos variados usos foi sempre superior a $1,37 \mathrm{kgf} /$ $\mathrm{cm}^{2}$, sendo que em alguns casos a resistência superficial atingiu 2,94 $\mathrm{kgf} / \mathrm{cm}^{2}$. Em áreas de capoeira (rodízio de terras), a capacidade de infiltração também é muito alta em torno de 21,5 $\mathrm{cm} / \mathrm{h}(\mathrm{n}=3)$ (THOMAZ \& HOMIAK, 2002).

\section{\begin{tabular}{lll}
\hline Parâmetros & Média & Desvio padrão
\end{tabular}}

\begin{tabular}{lcc}
\hline $\begin{array}{l}\text { Densidade aparente } \\
\left(\mathrm{g} / \mathrm{cm}^{3}\right)\end{array}$ & 0,84 & 0,03 \\
Porosidade total $(\%)$ & 68,5 & 1,1 \\
Resistência $\left(\mathrm{kgf} / \mathrm{cm}^{2}\right)$ & 0,48 & 0,23
\end{tabular}

Tabela 1 - Caracteristicas fisicas do solo avaliadas em superficie $(0-5 \mathrm{~cm})$

O monitoramento de umidade indicou variabilidade vertical (profundidade) e horizontal (lateralidade) da umidade ao longo da vertente. Quando as chuvas são regulares, não ocorre deficit hídrico em nenhum setor de vertente, pois há tendência de homogeneização da distribuição de umidade na vertente tanto, vertical quanto horizontal (Fig. 2.a). Por outro lado, no caso de haver irregularidade na precipitação alguns setores da vertente registram redução de umidade primeiro do que outros como segue: segmento retilíneo $\mathrm{T} 2$ e $\mathrm{T} 4$, topo $\mathrm{T} 1$, terraço fluvial $\mathrm{T} 6$, patamar T3 e segmento convexo T5 (Fig. 2.b).
Esse comportamento variável é devido aos solos serem rasos e haver pedregosidade no interior do horizonte. Isto aumenta a drenagem e reduz a capacidade de armazenamento de água. O patamar (T3) apresentou redução superficial de umidade, porém, o espessamento do solo e a menor pedregosidade nas profundidades acima dos $30 \mathrm{~cm}$ fizeram com que ele armazenasse mais água. Essa dinâmica é semelhante ao setor de vertente convexa/côncava (T5) com Cambissolo, moderadamente profundo com baixa pedregosidade, porém essa unidade é a que tem maior capacidade de retenção de umidade seguida pelo patamar (T3). 
$\mathbf{a}$

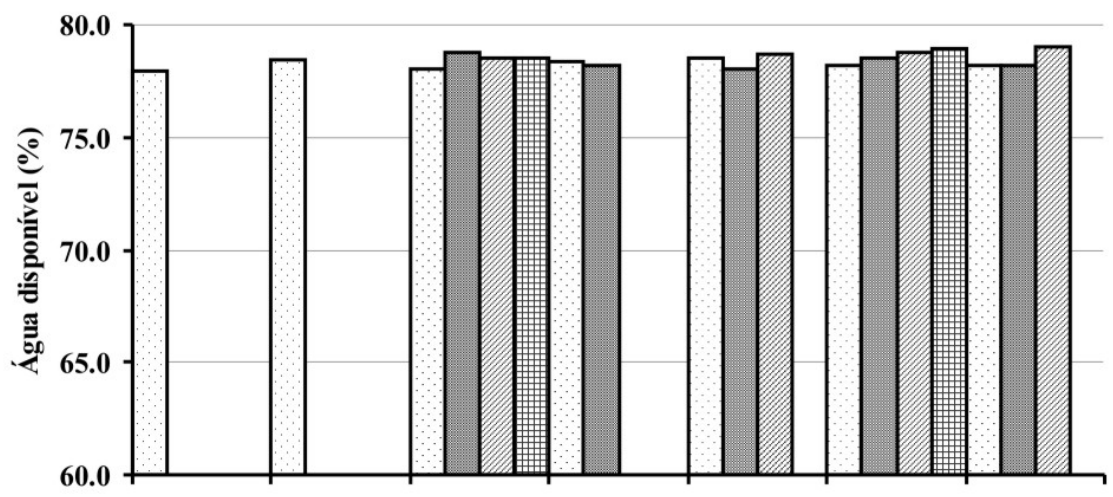

b

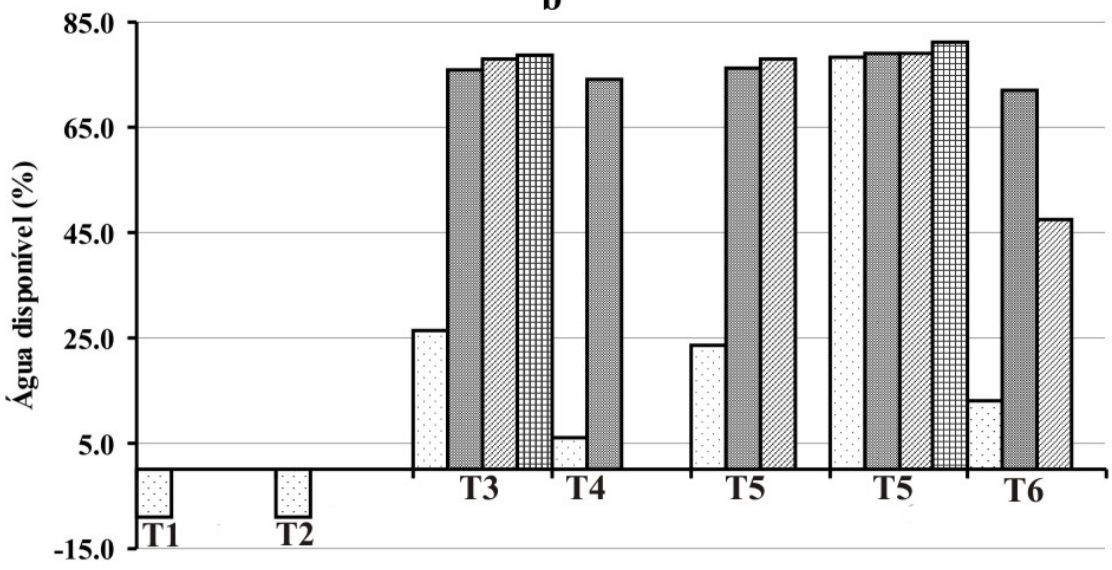

\section{口 $25 \mathrm{~cm} \square 50 \mathrm{~cm} \square 80 \mathrm{~cm}$ 田 $120 \mathrm{~cm}$}

Figura 2 - Monitoramento de água no solo em diferentes segmentos de vertente: a) situação de umidade; b) situação de déficit hídrico.

Nota: $(T)$ refere-se ao conjunto de tensiômetro instalado em cada segmento de vertente sendo: 1 topo (T1); 2 segmento retilíneo (T2); 3 patamar (T3); 4 segmento retilíneo (T4); 5 segmento convexo (T5); 6 terraço fluvial (T6) (Fig. 6 indica a distribuição dos tensiômetros ao longo da vertente).

Fonte: modificado a partir de Thomaz (2007, p. 48)

\subsection{Escoamento Superficial}

A precipitação total registrada em doze meses de monitoramento foi de $1524,9 \mathrm{~mm}$. O escoamento superficial mensurado, nas áreas com capoeira e queimada apresentou diferença estatística significante tanto no valor absoluto ( $\mathrm{mm})$ quanto no valor relativo (\%) $(P=<0,05 \%)$. O escoamento registrado na capoeira em doze meses de mensuração foi de $21,7 \mathrm{~mm}(1,4 \%)$, em contrapartida, a área queimada registrou 
escoamento de $35,5 \mathrm{~mm}(2,3 \%)$.

O padrão de escoamento (Fig. 3) nas duas áreas também foi distinto durante o monitoramento. Nos primeiros cinco meses (maio a setembro), após a área ter sido roçada e queimada, ocorreram as maiores taxas de escoamento. Nesse período, a área queimada registrou escoamento da ordem de $24,6 \mathrm{~mm}$ o que representou $69,3 \%$ do total acumulado em doze meses. A taxa de escoamento superficial foi de $5,5 \%$. Por outro lado, a área com capoeira teve escoamento de $7,7 \mathrm{~mm}$, ou $35,5 \%$ do total acumulado no período, já o coeficiente de escoamento foi de $1,7 \%$.
No período posterior (outubro a abril), o coeficiente de escoamento na área queimada foi de $1,0 \%(11,2 \mathrm{~mm})$, contra $1,3 \%(13,9 \mathrm{~mm})$ na área com capoeira. Comparando estes dois períodos, nota-se que o fogo utilizado para a limpeza do terreno causa distúrbio no topo do solo, isto é, redução na infiltração. Posteriormente, após lavagem superficial dos restos de queimada, em conjunto com a regeneração da vegetação a capacidade infiltração é gradativamente restabelecida, por conseguinte, o escoamento superficial é reduzido drasticamente.

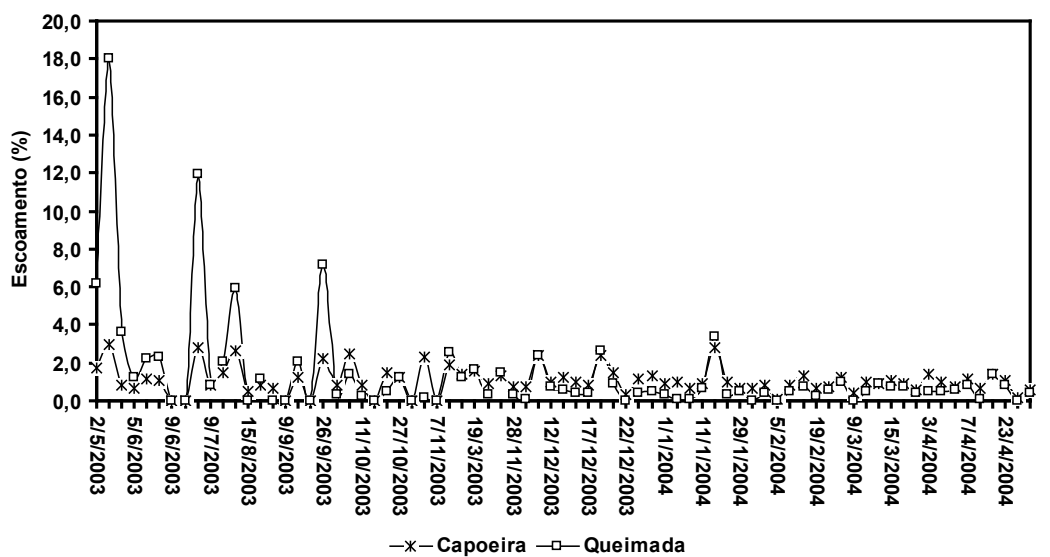

Figura 3 - Comparação entre o escoamento superficial nas áreas com capoeira e queimada

O efeito do fogo no solo causa diversas mudanças como: redução cobertura do solo; redução de matéria orgânica e estabilidade dos agregados; aumenta a erodibilidade do solo; aumenta a repelência de água no solo e reduz a capacidade de infiltração. Tais mudanças aumentam substancialmente o escoamento superficial e a perda de solo, sendo observado aumento rápido depois do fogo e decréscimo logo em seguida (SHAKESBY et al. 1996, De BANO, 2000, SHAKESBY et al. 2000). Este padrão foi observado na área em estudo (Fig. 3). Análise detalhada sobre o efeito do fogo na perda de solo foi apresentada por (THOMAZ, 2009).

\subsection{Estoque e Interceptação de Chuva em Serrapilheira}

A regeneração em sistema de rotação de terras começa a ocorrer no meio do ciclo da cultura (milho ou feijão). Inicialmente ocorre o surgimento de plantas herbáceas de ciclo anual, principalmente, buva amarela (Solidago chilensis Meyen), voadeira (Conyza bonariensis L.Cronq.), vassoura-mole (Senecio brasiliensis Less) e outras. Concomitante há aumento de espécie cespitosa como rabode-burro (Andropogon spp), capim caninha (Andropogon icanus), capim flexa (Trystachia 
chrysothirx), Capim barba-de-bode (Aristida pallens), caraguatá (Erydium spp) e gramíneas do gênero paspalum. Essas espécies são entremeadas por samambaias (Pteridium aquilinum), taquaras (Merostachys spp) e arranha-gato (Acacia plumosa). Gradativamente, a vassourinha espécie arbustiva (Miconia candolennas, Bacharis sp.) juntamente com a rebrota de espécies nativas como erva mate, pimenteira, canela e outras substituem as espécies herbáceas e vão constituindo o dossel principal com altura entre 3 a 5 metros (THOMAZ, 2005). Essa espécie arbustiva (vassourinha) foi predominante na área de capoeira durante o monitoramento.

Houve aumento do estoque de serrapilheira na superfície do solo no período monitorado (Fig. 4.a). Entre março de $2003\left(0,78 \pm 0,18 \mathrm{~kg} / \mathrm{m}^{2}\right)$ a março de $2004\left(1,28 \pm 0,23 \mathrm{~kg} / \mathrm{m}^{2}\right)$, o estoque registrado foi $64,1 \%$ superior, resultando em aumento de $0,5 \mathrm{~kg} / \mathrm{m}^{2}$ de serrapilheira. $O$ aumento de serrapilheira está relacionado com o processo de regeneração. Durante as coletas em março de 2003, verificou-se que a serrapilheira era: esparsa, irregular e pouco espessa $(<1 \mathrm{~cm})$ sobre a superfície do solo. Já, em março de 2004, a serrapilheira estava mais homogênea e a camada de detritos era superior a $1 \mathrm{~cm}$ de espessura.

A quantidade de serrapilheira mensurada em setembro $\left(1,67 \pm 0,49 \mathrm{~kg} / \mathrm{m}^{2}\right)$ foi superior ao registrado nas duas datas citadas anteriormente. Uma das possibilidades para o aumento do estoque de serrapilheira em setembro, com posterior diminuição em março de 2004 pode ter sido causado pela estação de inverno que antecedeu a coleta. Durante o inverno, o vento frio e as fortes geadas podem ter influenciado a queda das folhas. Nesta coleta ocorreu a maior variação amostral $29,6 \%$, o que demonstra, em parte, a heterogeneidade do recobrimento da serrapilheira, em compensação, as coletas realizadas em março de 2004 tiveram as menores variações 17,8\%, tendendo a uma distribuição mais homogênea do material sobre o solo.
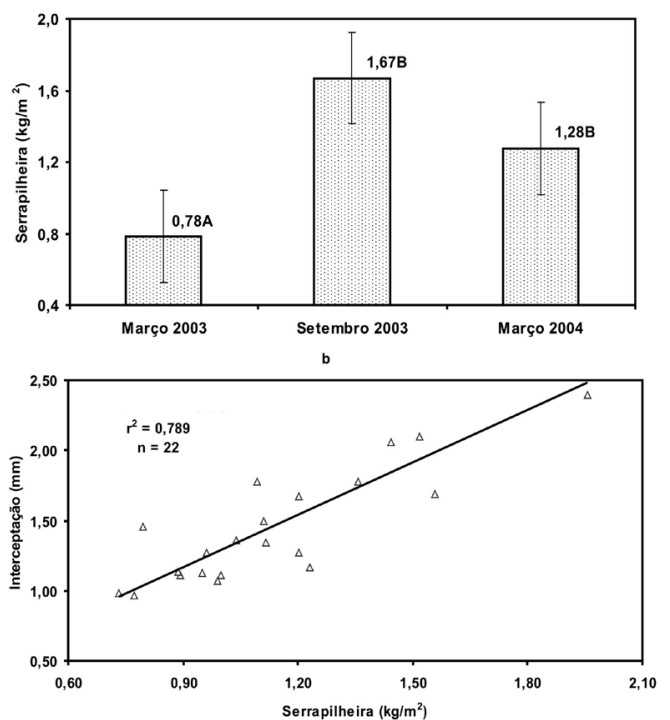

Figura 4 - a) evolução do estoque de serrapilheira; b) relação entre estoque de serrapilheira e interceptação.

Nota: Letras iguais não diferem estatisticamente ao nível de $5 \%$ pelo Teste $F$. 
A evolução do estoque de serrapilheira é importante para o balanço de água na vertente, uma vez que, a capacidade de interceptação de chuva e retenção de água está relacionada com a quantidade de material que recobre a superfície (Fig. 4.b). Após corrigir a umidade em capacidade de campo da serrapilheira $(18,8 \pm 2,8 \%)$, constatouse que ela pôde interceptar em média 1,2 $\pm 0,3 \mathrm{~mm}$, sendo que $82 \%$ das amostras interceptaram entre 0,8 a $1,9 \mathrm{~mm}$.

A interceptação por serrapilheira pode ser alta chegando a $10 \mathrm{~mm}$ (MADER \& LULL, 1968, citado por, WALLACE \& OLIVER, 1990). DUNNE \& LEOPOLD (1978) apontam que a capacidade de interceptação por serrapilheira depende da quantidade depositada sobre o solo, espessura e característica do material. Os autores reportam estudos em que a interceptação variou entre 2,5 a $4 \%$.

\subsection{Interceptação de Chuva e Estimativa de Balanço de Água em Vertente com Capoeira em Regeneração}

Foram registrados 68 eventos entre junho de 2003 a abril de 2004 (Tabela 2). A média de interceptação foi de $31,6 \%$, valor que equivale e até mesmo supera interceptações obtidas em diferentes ecossistemas florestais. LUDGREN \& LUDGREN (1979), após análise de vários estudos sobre interceptação de chuva, indicaram interceptação em floresta semidecídua com 1232 $\mathrm{mm}$ de precipitação média anual, de $3 \%$, já a floresta secundária com $3300 \mathrm{~mm}$ de precipitação média anual teve $57 \%$. Segundo os autores em floresta tropical a interceptação média fica em torno de 15 a 35\%. COELHO NETO (1995) reporta interceptação entre $17 \%$ e $24 \%$ em ecossistema montanhoso com floresta tropical secundária e precipitação média anual de $2300 \mathrm{~mm}$.

Neste estudo, a menor interceptação foi de $13,7 \%(31,0 \mathrm{~mm}, 14 / 12 / 03)$ e a maior $94,2 \%$ (3,9 mm, 01/11/03). Grosso modo, a ocorrência de interceptação menor do que $14,9 \%$ foi muito baixa (2 eventos 2,9\%), da mesma forma que interceptação superior $\geq 50 \%$ ( 9 eventos $13,2 \%$ ). As freqüências mais significativas de interceptação compreenderam o intervalo entre $15 \%$ a $34,9 \%$ ( 33 eventos $48,5 \%$ ) e o intervalo entre 35 a $44,9 \%$ (24 eventos $35,3 \%$ ).

\begin{tabular}{ccccccc}
\hline $\begin{array}{c}\text { Clas } \\
\text { se } \\
(\mathrm{mm})\end{array}$ & $\begin{array}{c}\text { Eve } \\
\text { ntos }\end{array}$ & $\begin{array}{c}\text { Precipitação } \\
(\mathrm{mm})\end{array}$ & $\begin{array}{c}\text { Atravessa } \\
\text { mento } \\
(\mathrm{mm})\end{array}$ & $\begin{array}{c}\text { Atravessa } \\
\text { mento }(\%)\end{array}$ & $\begin{array}{c}\text { Intercept } \\
\text { ação } \\
(\mathrm{mm})\end{array}$ & $\begin{array}{c}\text { Intercep } \\
\text { tação } \\
(\%)\end{array}$ \\
\hline $1-5$ & 7 & 3,6 & 2,4 & 66,7 & 1,2 & 33,3 \\
$5-$ & 19 & 7,4 & 4,4 & 59,5 & 3,0 & 40,5 \\
10 & & 14,9 & 9,5 & 63,8 & 5,4 & 36,2 \\
$\begin{array}{c}10- \\
20\end{array}$ & 22 & & 15,4 & 67,0 & 7,6 & 33,0 \\
$20-$ & 5 & 23,0 & & & & \\
30 & 5 & 33,9 & 25,1 & 74,0 & 8,8 & 26,0 \\
$30-$ & 5 & & & & & \\
40 & 10 & 61,7 & 44,2 & 71,6 & 17,5 & 28,4 \\
\hline 40 & 10 & 1395,8 & 954,7 & 68,4 & 441,1 & 31,6 \\
\hline Total & 68 & 135,4 &
\end{tabular}

Tabela 2 - Precipitação por classe, precipitação interna e interceptação em capoeira. 
O atravessamento aumenta à medida que o volume da chuva aumenta (Fig. 5.a). O volume de chuva diário teve mais influência no atravessamento do que a intensidade máxima da chuva (Fig. 5.b). Já que, algumas chuvas apresentam significativa intensidade, contudo, o volume precipitado é baixo, por conseqüência, a interceptação não é tão afetada.
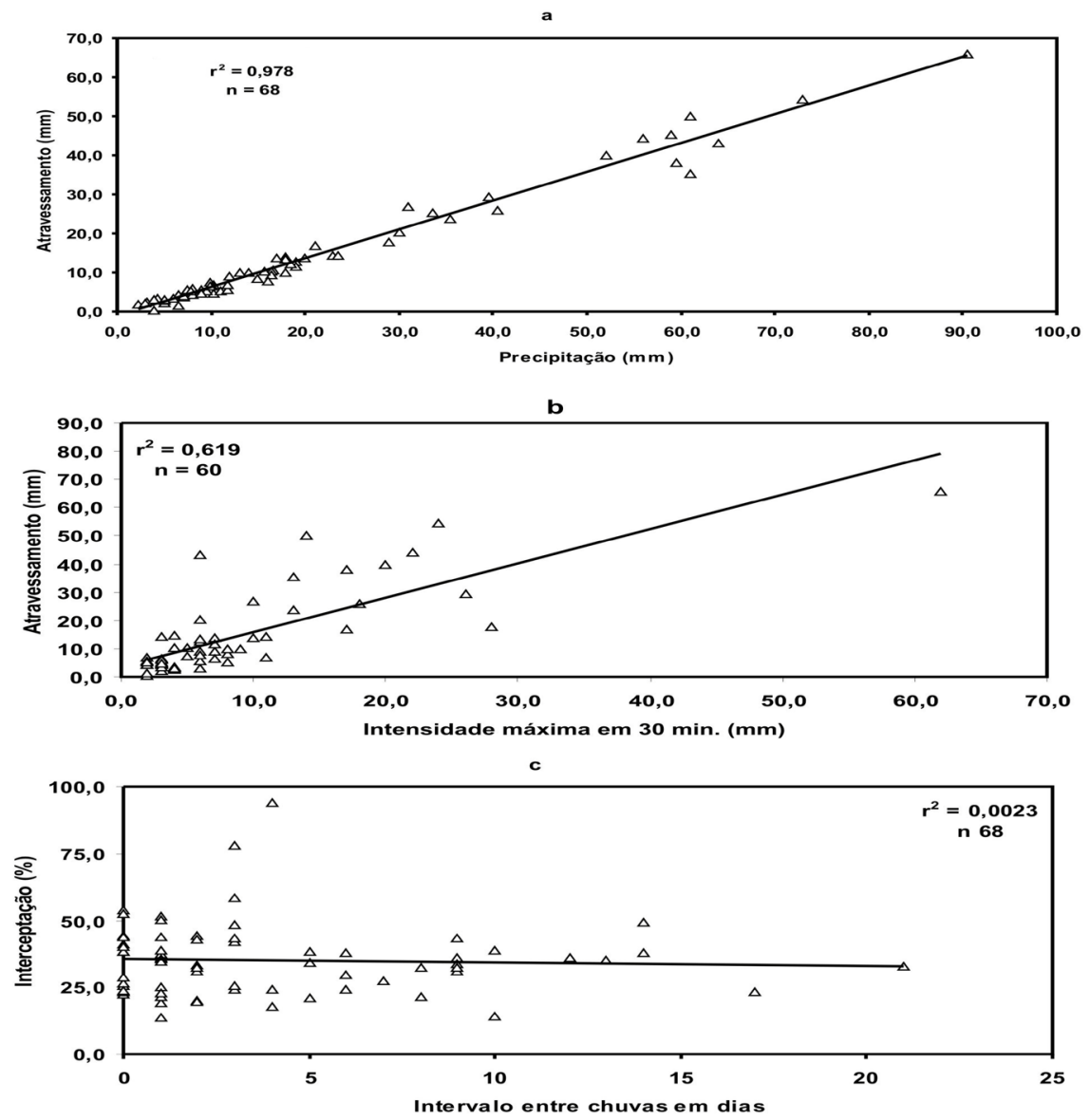

Figura 5 - a) Relação entre o total de chuva diária e atravessamento; b) relação entre intensidade da chuva em 30 minutos e atravessamento; c) relação entre o intervalo de chuva e interceptação.

A umidade antecedente do dossel tem papel importante na capacidade de interceptação, sendo que há tendência de redução de interceptação quando ele já se encontra saturado ou com alguma umidade (CROCKFORD \& RICHARDSON, 2000). No caso, da capoeira em regeneração o intervalo entre as chuvas não afetou a capacidade de interceptação, isto é, mesmo ocorrendo um evento precedido de outro (saturação) ou mesmo um evento que ocorreu após longo intervalo sem chuva (déficit) não ocorreu diminuição ou aumento de interceptação (Fig. 5.c). 
Baseado em equação de regressão $(y=0,735 x-1,056)$ a capoeira pode interceptar totalmente uma chuva de até $1,4 \mathrm{~mm}$ (Fig. 5.a). Este valor é igual ao estimado por Lima \& Leopoldo (1999), 1,4 mm, em floresta de mata ciliar (Cerradão) e inferior ao encontrado por HUBER \& OYARZÚN (1992) em área com Pinus $(2,1 \mathrm{~mm})$.

Baseado no monitoramento de interceptação (dossel e serrapilheira), e do escoamento superficial em capoeira foi possível estimar o balanço de água na vertente (Fig. 6). Destaca-se neste balanço a significativa capacidade de interceptação da chuva pelo dossel, o baixo coeficiente de escoamento e, sobretudo, a alta capacidade de infiltração. Considerando-se a interceptação do dossel em conjunto com a serrapilheira, pode-se chegar a uma interceptação aproximada de 36,6\%.

Desta forma, a capoeira, com aproximadamente três anos de regeneração, tem importante papel na hidrologia da vertente (balanço de água). O processo de roçar e queimar provocou aumento de entrada de mais água no solo. Haja vista, que a área depois de roçada e queimada apresentou maior escoamento superficial (ver Fig. 3), todavia a infiltração foi restabelecida depois de alguns meses. De qualquer modo, a taxa de escoamento superficial foi baixa em ambas as áreas (capoeira e queimada).

A cobertura superficial ao longo da vertente é extremamente variável (anisotropia). Além disso, o escalonamento do sistema vertente impõe fortes diferenças e rupturas na distribuição da energia potencial e, por extensão, na pressão hidrostática (THOMAZ E ROSS, 2006, THOMAZ, 2008). Os autores verificaram que devido a essas características ocorreu variação no escoamento superficial e produção de sedimento em cada compartimento de vertente.

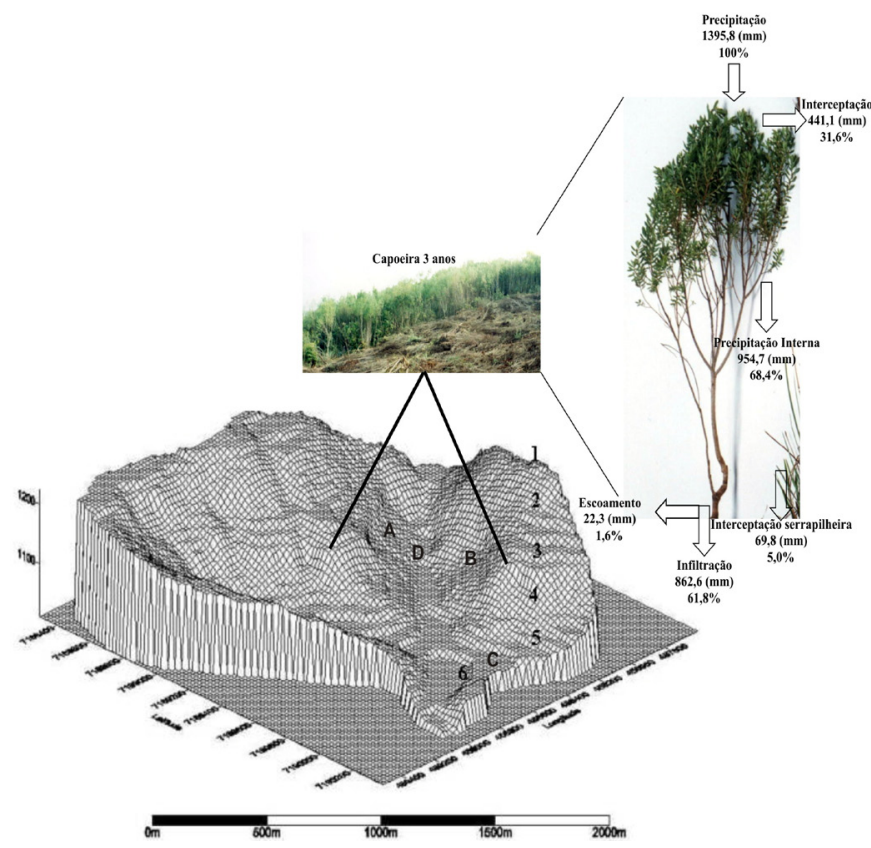

Figura 6 - Esboço do funcionamento hidrológico em capoeira com três anos de regeneração

Nota: Os números de 1 a 6 indicam setores de vertente onde foram instalados os tensiômetros. Número 4 indica local de monitoramento (interceptação e escoamento). Letras indicam locais referentes à figura 7. No balanço de água aproximado não foi possível estimar a perda por evaporação. 
Assim, a maior disponibilidade de água devido à redução da interceptação de chuva pela capoeira torna-se o principal responsável pelo aumento de instabilidade na vertente. Já que, as características da cobertura superficial, como: porosidade e pedregosidade interna tornam favorável à infiltração, resultando na transmissão rápida de água através de fluxo subsuperficial. Se por um lado, o solo possui rápida capacidade de transmitir água, por outro, é raso para armazenar e redistribuir lentamente a água recebida.

Esse processo é um dos prováveis responsáveis pela formação de canais na vertente (fluxo superficial aberto). Essa dinâmica ocorre devido ao colapso do topo de túneis rasos (pipe - fluxo subsuperficial raso), que se seguem com posterior coalescência das várias estruturas de abatimento. A partir do momento em que o fluxo superficial se instala na vertente, aumenta a competência do transporte de material e intensifica a dissecação das terras, por meio do aprofundamento do canal e pela expansão lateral da drenagem (cabeceira de dissecação). Nessa cabeceira de dissecação, ocorre transporte seletivo de materiais em que os sedimentos de frações mais finas, grânulos e seixos menores vão sendo introduzidos no canal, em contrapartida, os seixos maiores e blocos vão ficando isolados (permanência em situ). (Fig. 7.a, 7.b, 7.c) Essa dinâmica causa forte sedimentação do fundo do vale (Fig. 7.d).
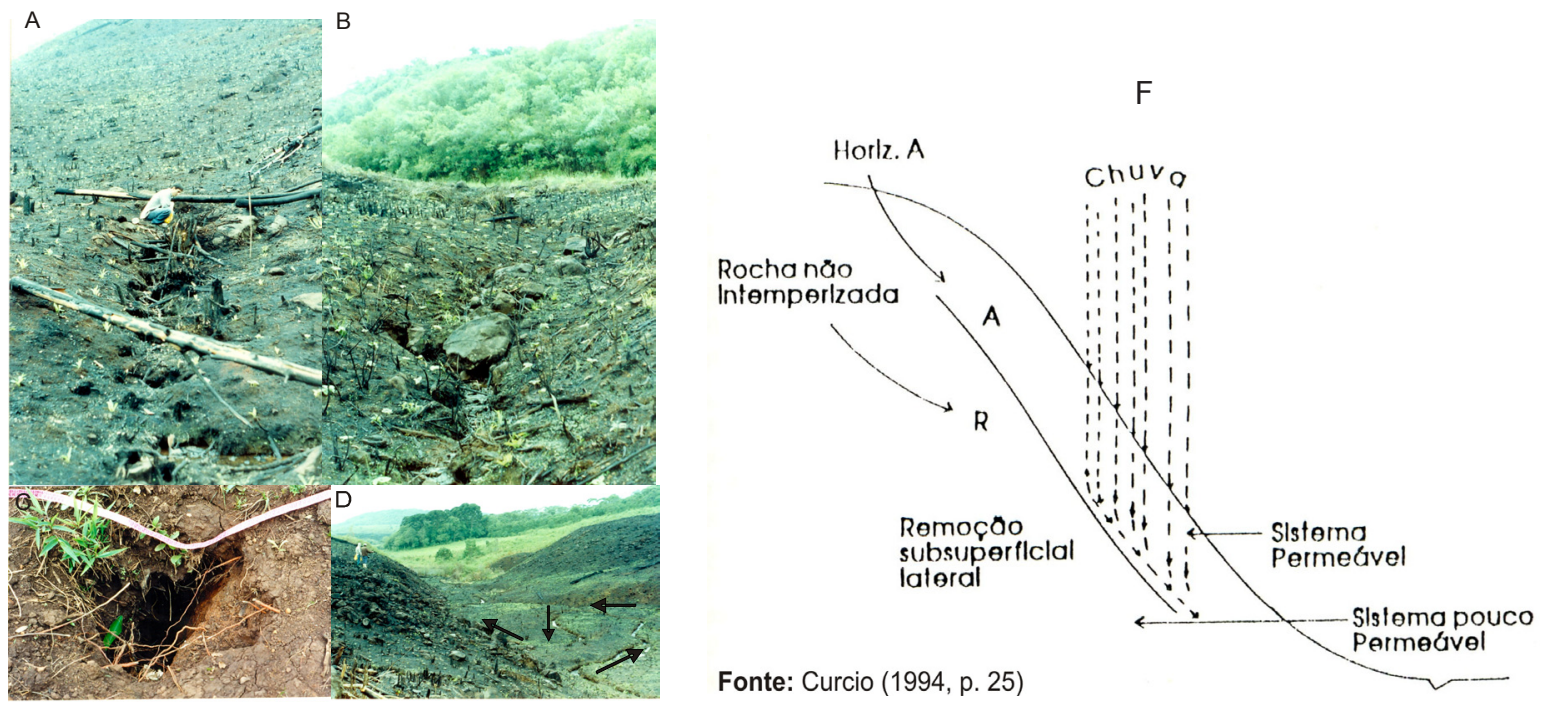

Figura 7 - a) área queimada com Pipe raso rompendo à superfície devido a colapso e coalescência do teto; b) área queimada com Pipe raso transformado em canal aberto conectado à drenagem; c) Pipe profundo rompendo à superfície devido à diminuição de permeabilidade e aumento da pressão hidrostática. Deste ponto em diante, a água escoa sobre a superfície do terreno e se junta ao fluxo de retorno; d) Meandro em canal de segunda ordem indicando a forte sedimentação no fundo do vale; f) Funcionamento hidrológico em sistema com solo litólico com contato lítico.

Nota: Pontos (A, B, C e D) estão localizados na figura 6. 
CURCIO (1994) em estudos no Segundo Planalto Paranaense (Centro Sul do Paraná) destacou em termos teóricos que em sistema pedológico do tipo litólico com contato lítico a mudança de gradiente hidráulico torna esse ambiente propício ao movimento de massa. O autor ressalta, ainda que: neste tipo de contato deve-se considerar a possibilidade de maiores perdas de colóides e bases através de escorrimento subsuperficial lateral (CURCIO, 1994, p.25) (Fig. 7.f).

$\mathrm{Na}$ área de estudo o processo hidrológico subsuperficial (pipe) ocorre em dois domínios distintos na vertente, por consequência, possuem fatores controladores diferentes. Baseado em DALRYMPLE et al. (1968) propõe-se a seguinte dinâmica:

a) Unidade 5 de acordo com DALRYMPLE et al. (1968) refere-se a meia vertente onde predomina processos de transporte de material (movimento de massa e escoamento difuso), sendo o escoamento subsuperficial importante. Nestes setores pode existir contraste entre solos mais profundos e rasos. Na área de estudo esse processo predomina devido à mudança de gradiente hidráulico entre o horizonte superficial (permeável) e o contato líticolitóide logo abaixo (impermeável). Neste setor de vertente os pipes são rasos e rapidamente tornamse canais abertos. As chuvas intensas influenciam a resposta hidrológica desses fluxos. A frequente roçada e a queima de capoeira aumentam a instabilidade neste setor e aceleram essas formas erosivas (7.a e 7.b).

b) Unidade 6 de acordo com DALRYMPLE et al. (1968) refere-se ao sopé de vertente recoberta com material coluvial. Predomina processo de redistribuição e transporte de material superficial proveniente de montante por meio de fluxo difuso e subsuperficial. Neste setor de vertente ocorre a heterogeneidade dos horizontes pedológicos, sendo os processos hidrológicos são mais complexos envolvendo: anisotropia dos materiais (horizontes); aumento da quantidade de água proveniente de montante (área de contribuição); aumento de pressão hidrostática no sopé de vertente, somado a elevação do lençol freático raso; os fluxos em forma de pipe se junta ao fluxo saturado de retorno em áreas próximas ao canal fluvial. Neste caso os pipes são mais profundos preservando os dutos por longas distâncias ( $50 \mathrm{~m}$ ou mais), pois o colapso de teto é mais lento. A resposta hidrológica desses fluxos está mais relacionada a chuvas contínuas que causam saturação do solo. A frequente roçada e a queima de capoeira têm influência menos intensa na dinâmica dessas formas erosivas (Fig. 7.c).

\section{Conclusões}

As condições físicas, densidade aparente e porosidade total, do solo na vertente com sistema de rotação de terras favorecem a infiltração. Porém, os solos rasos e pedregosos (litólicos e cambissolos), possuem baixa capacidade de armazenamento de água. Essas características somadas ao escalonamento das formas de relevo resultam em dinâmica hidrológica distintas em cada setor de vertente.

A roçada e a queima da capoeira aumentam inicialmente o escoamento superficial na vertente. Posteriormente, a infiltração é restabelecida reduzindo o escoamento superficial, por extensão, aumenta a entrada de água no solo. Depois de três anos de regeneração a capoeira atinge alta capacidade de interceptação (dossel e serrapilheira). Constatou-se que a dinâmica do sistema de rotação aliado a complexidade geomorfopedológica da vertente induz processos hidrológicos, notadamente subsuperficiais. Esses processos são fundamentais para o desencadeamento de instabilidade nas vertentes através do surgimento e expansão de cabeceiras de canais de primeira ordem. Tais processos são importantes ao entendimento da evolução das paisagens contemporâneas na região de Guarapuava.

\section{Agradecimentos}

Agradeço ao CNPq, pelo apoio financeiro durante o desenvolvimento da pesquisa de doutorado. Ao Professor Jurandyr Luciano Sanches Ross pela orientação ao longo da pequisa. A Joel Silvério de Araújo pela colaboração na manutenção e auxílio no monitoramento dos experimentos. 


\section{Bibliografia}

ANDERSON, M. G. \& BROOKS, S. M. 1996. Hillslope processes: research prospects. In: Anderson, $M$. G. \& Brooks, S. M. (eds.). Advances in hillslope processes. Baffins Lane, Chichester, John Wiley \& Sons. p. $5-32$.

ANDERSON, M. G. \& BURT, T. P. 1990. Process studies in hillslope hydrology: an overview. In. ANDERSON, M. G. \&

BURT, T. P. (eds.). Process studies in hillslope hydrology. Baffins Lane, Chichester, John Wiley \& Sons. p. $1-8$.

BORGGAARD, O. K.; ABDUL. G. \& PETERSEN, L. 2003. Sustainability appraisal of shifting cultivation in the Chittagong Hill Tracts of Bangladesh. Ambio, 32: $118-123$.

BROOKS, S. M. 2003. Slopes and slope processes: research over the past decade. Progress in Physical Geography, 27 (1): 130-141.

BRYAN, R. B. \& JONES, J. A. A. 1997. The significance of soil piping processes: inventory and prospect. Geomorphology, 20: 209-218.

CHORLEY, R. J. 1964. The nodal position and anomalous character of slope studies in geomorphological research. Geographical Journal, 130 (1): 70-73.

COELHO NETO, A. L. 1995. Hidrologia de encosta na interface com a geomorfologia. In: Guerra, A. T. G. \& Cunha, S. B. (eds.). Geomorfologia: uma atualização de bases e conceitos. Rio de Janeiro, Bertrand Brasil, p. 93-148.

CROCKFORD, R. H. \& RICHARDSON, D. P. 2000. Partitioning of rainfall into throughfall, stemflow and interception: effect of forest type, ground cover and climate. Hydrological Processes, 14: 2903-2920.

CURCIO, G. R. 1994. Solos de encosta de baixa aptidão agrícola da área de estudo. In: MERTEN, G. H. (ed.). Manejo de solos de baixa aptidão agrícola no centro-sul do Paraná. Londrina, Instituto Agronômico do Paraná, Circular n. 84, p. 23-39.

DALRYMPLE, J. P.; BLONG, R. J. \& CONACHER, A. J. 1968. A hypothetical nine unit land surface model. Zeitschrift fur Geomorphologie, 12: 60-76.

De BANO, L. F. 2000. The role of fire and soil heating on water repellency in wildland environments: a review. Journal of Hydrology, 231-232: 195-206.

DUNNE, T. \& LEOPOLD, L. B. 1978. Water in environmental planning. New York, W. H. Freeman and Company, 818p.

EMBRAPA. Centro Nacional de Pesquisa de Solo. 1997. Manual de métodos de análise de solos. - 2 ed. Rio de Janeiro, Embrapa-CNPS, 212p.

GRAU, A. \& BROWN, A. D. 2000. Development threats to biodiversity and opportunities for conservation in the mountain ranges of upper Bermejo River Basin, NW Argentina and Bolívia. Ambio, 29: 445-450.

HÖLSCHER, D.; LUDWIG, B.; MÖLLER, R.F. \& FÖSLTER, H. 1997. Dynamic of soil chemical parameters in shifting agriculture in the Eastern Amazon. Agric. Ecosyst. Environ. 66: 153-163

HUBER, A. M. \& OYARZÚN, C. E. 1992. Redistribución de las precipitaciones en un bosque siempreverde del sur de Chile. Turrialba 42 (2): 192-199.

JONES, J. A. A., RICHARDSON, J. M. \& JACOB, H.J. 1997. Factors controlling the distribution of piping in Britain: a reconnaissance. Geomorphology, 20: 289-306.

KIRKBY, M. J. 1978 (ed). Hillslope Hydrology. New York, John Wiley \& Sons, 389p.

LIMA, P. R. A. \& LEOPOLDO, P. R. 1999. Interceptação 
de chuva por mata ciliar na região central do estado de São Paulo. Energia na Agricultura, 14 (3): 25-33.

LUDGREN, L. \& LUDGREN, B. 1979. Rainfall, interception and evaporation in the Mazunbai Forest Reserve, West Usambara Mts., Tanzania and their importance in the assessment of land potential. Geografiska Annaler, 61: 157-178.

MADER, D. L. \& LULL, H. W. 1968. Depth, weight and water storage of the forest floor. North East Forest Experimental Station, Paper, 109.

McCAIG, M. 1985. Soil properties and subsurface hydrology. In: Richards, K.S.; Arnett, R. R. \& Ellis, S. Geomorphology and soils. London, Allen \& Unwin. p. 121-140.

MENDES, W. \& CASTRO, A. F. 1984. Limitações do uso dos solos do Estado do Paraná por suscetibilidade à erosão. Rio de Janeiro, EMBRAPA-SNLCS, 14p.

MORGAN, R.P.C. 2005. Soil erosion and conservation. Blackwell, Oxford, 304p.

REICHARDT, K. 1990. A água em sistemas agrícolas. São Paulo, Monole, 188p.

SHAKESBY, R. A.; BOAKES, D. J.; COELHO, C. O. A.; GONÇALVES, A. J. B. \& WALSH, R. P. D. 1996. Limiting the soil degradational impacts of wildfire in pine and eucalyptus forests in Portugal. Applied Geography, 16: 337-355.

SHAKESBY, R.A.; DOERR, S.H. \& WALSH, R.P.D. 2000. The erosional impact of soil hydrophobicity: current problems and future research directions. Journal of Hydrology, 231-232: 178-191.

SIDLE, R. C. \& ONDA, Y. 2004. Hydrogeomophology: overview of an emerging science. Hydrological Processes, 18: 597-602.

THOMAZ, E. L. \& HOMIAK, M. 2002. Ensaios de capacidade de infiltração de água em diferentes tipos de usos do solo na bacia do Rio Guabiroba, Guarapuava, PR. UNICENTRO, Guarapuava, 44p. (Relatório de iniciação científica).

THOMAZ, E. L. \& VESTENA, L. R. 2003. Aspectos Climáticos de Guarapuava - PR. Guarapuava, Editora UNICENTRO, 106p.

THOMAZ, E. L. \& ROSS, J. L. S. 2006. Processos hidrogeomorfológicos em vertente com solos argilosos rasos em Guarapuava-PR, Brasil. Revista Brasileira de Geomorfologia, 7 (2): 23-38.

THOMAZ, E. L. 2005 . Processos hidrogeomorfológicos e o uso da terra em ambiente subtropical - Guarapuava - PR. São Paulo, 297f. Tese de Doutorado em Ciência, área Geografia Física, Faculdade de Filosofia Letras e Ciências Humanas, DEPARTAMENTO DE GEOGRAFIA, UNIVERSIDADE DE SÃO PAULO.

THOMAZ, E. L. 2007. Compartimentos geomorfológicos e produção de milho em agricultura de subsistência, Guarapuava-PR: avaliação exploratória. Sociedade \& Natureza, 19 (1): 45-54.

THOMAZ, E. L. 2009. The influence of traditional steep land agricultural practices on runoff and soil loss. Agriculture, Ecosystems \& Environment, v. 130, p. $23-30$.

VIERA, S. 1999. Estatística experimental. São Paulo, Atlas, 185p.

WALLACE, J. S. \& OLIVER, H. R. 1990. Vegetation and hydroclimate. In: ANDERSON, M. G. \& BURT, T. P. (eds.). Process studies in hillslope hydrology: an overview. Baffins Lane, Chichester, John Wiley \& Sons. p. $9-41$.

WALSH, R. P. D. \& HOWELLS, K. A. 1988. Soil pipes and their role in runoff generation and chemical denudation in a humid tropical cathment in Dominica. Earth Surface Processes and Landforms, 13: 9-17. 